\title{
AREAS OF AUDIT OF INVENTORIES OF THE AIRLINE
}

\section{Hudyma Vlada ${ }^{1}$ \\ Bondarenko Olga ${ }^{2}$}

DOI: https://doi.org/10.30525/978-9934-571-89-3_125

Directions of realization of audit of supplies that will allow promoting financial safety of enterprise are in process considered: audit of receipt of supplies, audit of leaving of supplies, taking of inventory of supplies and reflection of supplies in accounting. The proposed directions of the audit will enable the auditor to cover all the main aspects of inventory accounting at the enterprise, to investigate the correctness, timeliness and legality of the inventory records, to timely detect violations, and conduct a qualitative audit of the enterprise.

\footnotetext{
${ }^{1}$ National Aviation University, Ukraine

${ }^{2}$ National Aviation University, Ukraine 
The activity of each airline is directly related to the movement of inventories. A prerequisite for ensuring their preservation and correctness of accounting is the timely and correct documentation of transactions in the movement of inventory of the enterprise (receipt, disposal, storage). Therefore, it is important to check the correctness, timeliness and legality of inventory accounting.

The main principles for the formation of inventory accounting are defined in the Regulation (Standard) of accounting 9 "Stocks". Reserves are assets held by an enterprise for resale in the ordinary course of business; they are in the process of production; kept for own use, etc.

As the determining factor for ensuring competitiveness in the market of manufactured products is the condition, formation and use of stocks, which is precisely because of this there is a need for conducting an audit.

Proceeding from the requirements of the current legislation, the purpose of the audit of inventories is the statement by the independent auditor of the adequacy of the financial information on the movement and the balance of production passwords at the enterprise in all material aspects in the regulatory documents regulating the procedure for its preparation and provision to users.

The rational organization of the management of the audit process provides for the observance of certain areas of the audit of production stocks. List of such directions is given in Figure 1.

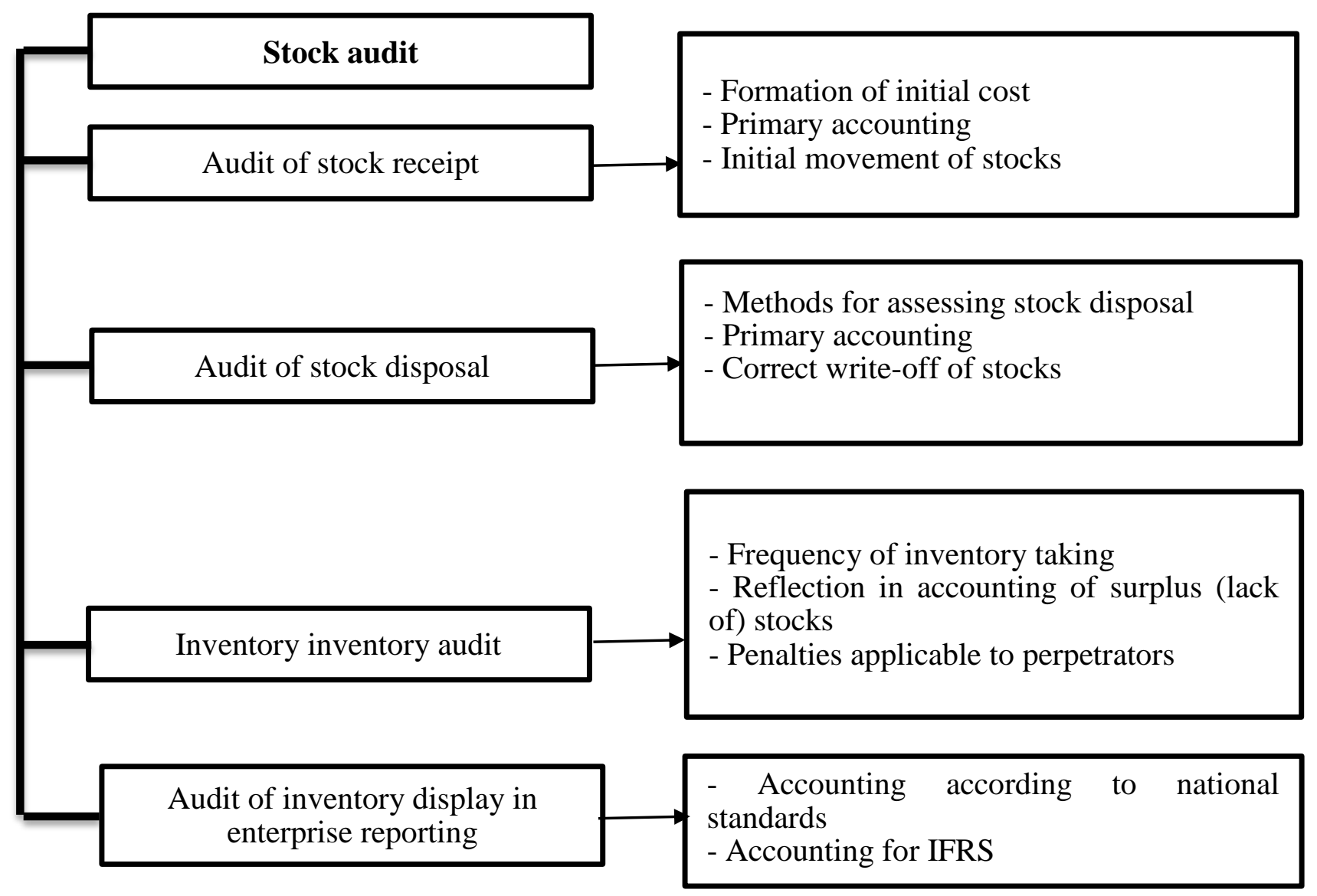

Figure 1. Areas of audit of inventories of the airline 
During the audit of stock inflows, the audit firm first checks the correctness of the formation of their initial value, on which they are credited to the balance sheet of the enterprise. To do this, use the following operations:

- A check is made of the availability and compliance of the primary documents on the receipt of stocks, which are confirmed by the conduct of business transactions;

- Do the stocks correspond to the qualitative and quantitative characteristics indicated in the documents on their receipt;

- Verification of the expense incurred, which is included in the original cost;

- Verification of the absence of expenses in the initial cost of inventories, which according to the law should not be included in it (indirect taxes, which are reimbursed to the customer-the enterprise, etc.);

- Verification of the composition of costs, from which the charged personal value of the inventory is charged (compliance with clause 9 of $\mathrm{P}(\mathrm{C}) \mathrm{BO} 9$ "Stocks");

- verification of the conformity of the formation of the initial value to the legally defined requirements depending on the sources of the receipt of inventories (in particular, the initial value in exchange for similar assets is equal to the book value of the transferred stock, and not the fair value of the received stocks, as in the exchange of non-specific assets, etc.).

Also, when the stocks are transferred, an audit of the initial accounting is carried out. At this stage, the correctness of the design and availability of primary records of stock records and the correctness of their application is checked. Such documents include: a magazine on cargo registration, a journal of registration of power of attorney, limit-collecting cards, inventory description of inventory, IBC accounting card, TTN, acts of acceptance of inventory and other assets. In addition to the primary documents, it is necessary to check the availability of contracts of full financial responsibility.

In this direction, the correct and timely retrieval and internal movement of stocks are checked. The audit firm establishes the legality of actions that are related to the movement of inventories, and whether there are no significant violations and errors in accounting and reporting.

When auditing internal stock transfer operations, auditors should pay attention to the following significant points: the reasons and the need for relocation; documentary design; fixing responsibility as a result of the transfer of stocks; the correctness of the write-off of the relevant stocks for individual MFOs; the correspondence between primary documents and material reports; mapping of movement in analytical accounting.

The second direction is the audit of stock disposal. At this stage, it is necessary to establish the actual application of the method for assessing the release of inventories (the identified cost of the corresponding unit of inventory, the weighted average cost of production, regulatory costs, sales prices, FIFO) and its compliance with the method, which is specified in the order on the accounting policies of the enterprise. In case of re-issuance of stocks to third parties, it is checked on what basis the vacation was made and under which conditions the sale took place, while the data of the primary documents are checked; the absence of the use of methods that are prohibited 
by law or those that have lost their validity (LIFO method); the correctness of determining the average percentage of trade margins, etc.

The auditor establishes observance of serial documentary registration of records and correctness of qualitative indicators for production of stocks.

The next direction is the inventory inventory audit. At this stage, the observance of terms, order, documentary and reflection in the account of the results of inventory inventory checks; orders for inventory, inventory descriptions, acts of controlling valuables, written explanations of material-responsible persons and minutes of meetings of inventory commissions.

During the audit, the audit firm carries out the frequency of inventory (once a year, time 1 time per year, 1 time a year); Whether to carry out unplanned (sudden) inventory separate mice departments, groups, in separate places of storage and in the reporting, etc. at the enterprise. Inventory pricing at an enterprise is carried out in case of a change in the material-responsible person, before drawing up annual financial statements, etc.

Do not carry out obligatory inventory or its carrying out with violations concerning the application of administrative and / or disciplinary liability to employees of the enterprise who commit violations.

The data of the financial statements, compiled without carrying out the inventory, may prove to be unreliable, which, in turn, will result in the calculation of fines and penalties stipulated by the tax code.

It is also necessary to determine how the excess (inventory) of inventories is recorded in inventories and to identify what has led to such a situation and to determine the consequences.

During the audit, inventory reporting in the auditor's responsibility to verify the compliance of the synthetic and analytical accounting data, the main book, the reporting; Verify the probability of data on stock stays in a fixed spot: whether to show inventories at the lowest estimate: either by the initial value or by the purity of the value of inventory sale; Check the accuracy of the information on the stocks that are displayed in the premise to the final vision, which corresponds to the norm $\mathrm{P}(\mathrm{C}) \mathrm{BO} 9$ "Stocks".

Consequently, the application of the proposed areas of audit will allow the audit firm to conduct a more qualitative audit at the enterprise and will allow guidance to the management to improve and expand the control over the accounting and movement of the enterprise inventory.

\section{References:}

1. Bardash S. Subject and Object of Control as a Field of Scientific Knowledge and Practical Activity / S. Bardash // Accounting and Audit. - 2008. - No. 6. - P. 55-61.

2. Davydov G. M. Audit: [curriculum vitae] manual.] / G. M. Davydov. - [3rd form, ster.]. - K.: T-“Knowledge”, KOU, 2002. - 363 p.

3. Stocks: P (c) BO 9, Approved by the order of the Ministry of Finance of Ukraine dated October 20, 1999 No. 246. Access mode: http://www.nibu.factor.ua/info/instrbuh/psbu9/ 